\title{
Sports Psychiatry - Journal of Sports and Exercise Psychiatry
}

\author{
Malte Christian Claussen ${ }^{1,2,3}$, Andres Ricardo Schneeberger ${ }^{1,3,4}$, \\ and Markus Gerber ${ }^{5}$ \\ 1 Department of Psychiatry, Psychotherapy and Psychosomatics, Psychiatric University Hospital Zurich, University of Zurich, Switzerland \\ 2 Private Clinic Wyss AG, Münchenbuchsee, Switzerland \\ 3 Adult Psychiatry, Psychiatric Services Grisons, Chur, Switzerland \\ 4 Department of Psychiatry and Behavioral Sciences, Albert Einstein College of Medicine, New York City, USA \\ 5 Department of Sport, Exercise and Health, University of Basel, Switzerland
}

The development of sports psychiatry started around the early nineties [1]. In 1994, the International Society of Sports Psychiatry (ISSP) was founded, the first sport psychiatric society [2].

Ira Glick, Todd Stull and Alan Currie (2022) describe in their article and in this first issue of Sports Psychiatry - Journal of Sports and Exercise Psychiatry the remarkable development of sports psychiatry in the United States and internationally in the last three decades, which we are very pleased and honored of [3].

Since the beginning of this century, sports psychiatry has also developed rapidly in the German speaking countries in Europe, and various sports psychiatric networks have formed, e.g., a department within the German Association for Psychiatry and Psyotherapy, Psychosomatics and Neurology, as well as national societies for sports psychiatry in Switzerland, Germany and Austria.

The Swiss Society for Sports Psychiatry and Psychotherapy (SSSPP) was founded in 2019 as the first national society for sports psychiatry [4]. The purpose of the SSSPP is to promote sports psychiatry and psychotherapy over the lifespan in Switzerland, in competitive sports and in the general population.

The launch of Sports Psychiatry - Journal of Sports and Exercise Psychiatry will take place with the first International Conference on Sports Psychiatry (ICSP), which will be held online on January 14-15, 2022 [5]. This first issue of Sports Psychiatry contains the abstracts of the ICSP 2022.

\section{Sports psychiatry and fields of activity}

Today, physical activity in prevention and therapy of mental illnesses as well as mental health issues in competitive sports are established areas in sports psychiatry [6]. Other frequently considered interests for sports psychiatry are sports-specific mental diseases in popular sports [7].

Sports psychiatric issues could be also found in the field of sports medicine [7], as well as in paramedical disciplines such as clinical psychology, sports and exercise psychology, and sports and exercise science. The knowledge and skills of these disciplines are paramount in the interdisciplinary and interprofessional approach to sports psychiatry and for sports psychiatrists.

Therefore, sports psychiatry should further be developed (i) as a subspecialty of child, adolescent and adult psychiatry, (ii) in the field of sports medicine and (iii) in close cooperation with paramedical disciplines [4, 7].

In the conception of Sports Psychiatry, we have considered this interdisciplinary and interprofessional approach.

\section{Launch of Sports Psychiatry}

While the attention to the field of sports psychiatry has increased significantly in recent years, up to this date there is no corresponding specialist journal. This fact renders it difficult to publish articles in the field of sports psychiatry as well as making them visible to the proper target group.

The aim of the SSSPP was to create an international journal and thus targeting the greatest possible visibility and dissemination of publications in all aspects of sports psychiatry.

Accordingly, the journal's contents will be international, as will be its Editorial Board. With the launch of the journal, the Editorial Board will be continuously enlarged and completed with renowned international clinicians and scientists in the field of sports psychiatry. Likewise, the various networks and societies for sports psychiatry will be approached for support of the journal. 
Interested professionals, as well as networks and societies who want to participate are more than welcome and could also contact the Editor-in-Chief directly.

\section{Aims and Scope}

Sports Psychiatry-Journal of Sports and Exercise Psychiatry is an international open access, peer-reviewed journal providing a platform for advances in all aspects of sports psychiatry, including but not limited to the diagnosis, management, therapy, and prevention of mental disorders in competitive and popular sports, as well as to physical activity, exercise and sport in the prevention and treatment of mental disorders.

The journal's aim is to publish high-quality original research articles, consensus statements, meta-analyses, reviews, editorials, and commentaries for a wide audience of healthcare professionals and researchers interested in the field of sports psychiatry. Sports Psychiatry is the first specialist journal in the field of sport psychiatry.

\section{Key Data of the Journal}

The publisher Hogrefe AG will hold the title rights of Sports Psychiatry-Journal of Sports and Exercise Psychiatry, as part of its journal portfolio.

Target audiences of Sports Psychiatry are sports psychiatrists, child and adolescent psychiatrists, adult psychiatrists, sports physicians, paediatricians and general practitioners, clinical psychologists, sports/exercise psychologists, mental trainers and other professional coaches, exercise therapists, physical therapists and sports physical therapists, sports/exercise scientists, other disciplines, plus sports organizations and associations.

The scope of the journal is four issues per year with 5-6 articles plus editorial. As the journal is being established, abandoning the issue structure will be considered and articles will be published continually, aiming at a timely publication of submitted work.

Manuscripts are welcome at any time and should be submitted with Editorial Manager ${ }^{\circledR}$. The journal language is English, and only manuscripts in English will be considered.

Initiatives for special issues and topics are also welcome at any time.

\section{Sponsoring}

Sponsoring, e.g., from institutions, foundations or companies are always welcome and will help us to support all who do not have access to article processing charge (APC) funding.

Currently, there is a waiver program in place, mainly sponsored by Hogrefe AG. Additionally, the SSSPP also supports the journal financially.

\section{Outlook}

We are very grateful for the possibility to develop the first journal in the field of sports psychiatry and we are looking forward to providing a platform for advances in all aspects of sports psychiatry.

\section{References}

1. Begel D. Sport psychiatry twenty-four years later. Int Rev Psychiatry. 2016;28:547-550.

2. International Society for Sports Psychiatry [Internet]. International Society for Sports Psychiatry; [cited 2021 Nov 13]. Available from: https://www.sportspsychiatry.org

3. Glick I, Stull T, Currie A. Development of Sports Psychiatry in the United States and Internationally. Sports Psychiatry. 2022;1:3-5.

4. Claussen MC. Swiss Society for Sports Psychiatry and Psychotherapy SSSPP. SEMS Journal. 2020;68:5-8.

5. International Conference on Sports Psychiatry - ICSP 2022 [Internet]. Swiss Society for Sports Psychiatry and Psychotherapy; [cited 2021 Nov 13]. Available from: https://kongress. sgspp.ch/2022/en/

6. Ströhle A. Sports psychiatry: mental health and mental disorders in athletes and exercise treatment of mental disorders. Eur Arch Psychiatry Clin Neurosci. 2019;269:485-498.

7. Claussen MC. Sports psychiatry: discipline and fields of activity. Dtsch Z Sportmed. 2021;72:259-260.

\section{Acknowledgement}

We would like to gratefully thank Andrea Alferi and Stefan Schüpbach at Hogrefe AG for their support.

\section{Author note}

Parts of this editorial were published previously with the launch of the journal.

\author{
Malte Christian Claussen, MD \\ Editor-in-Chief Sports Psychiatry \\ President of the Swiss Society for Sports Psychiatry and Psy- \\ chotherapy (SSSPP) \\ Department of Psychiatry, Psychotherapy and Psychosomatics \\ Psychiatric University Hospital Zurich \\ University of Zurich \\ Lenggstrasse 31 \\ 8032 Zurich \\ Switzerland
}

malte.claussen@pukzh.ch

\section{Markus Gerber, PhD}

Associate Editor Sports Psychiatry

Department of Sports, Exercise and Health

University of Basel, Switzerland

\footnotetext{
Andres Ricardo Schneeberger, MD

Associate Editor Sports Psychiatry

Adult Psychiatry

Psychiatric Services Grisons

Chur, Switzerland
} 